\title{
QUALIDADES SONORAS DE EXPRESSÕES VOCAIS DE CRIANÇAS COM AUTISMO EM UMA OFICINA TERAPÊUTICA DE MÚSICA
}

\section{SOUND QUALITIES OF VOCAL EXPRESSIONS BY CHILDREN WITH AUTISM IN A MUSIC THERAPEUTIC GROUP}

Daniel Camparo Avila

E-mail para correspondência: dcamparo@psico.edu.uy

\begin{abstract}
RESUMO
As qualidades sonoras das expressões vocais de sujeitos com autismo vêm recebendo uma crescente atenção pela comunidade acadêmica e clínica. O presente artigo apresenta os resultados relacionados a este tema a partir de uma pesquisa sobre uma oficina de música oferecida a crianças com autismo. Duas vocalizações ocorridas nas sessões da oficina são apresentadas, bem como suas respectivas análises acústicas. Discute-se as características comuns de vocalizações associadas ao autismo, bem como o desenvolvimento da função psíquica da voz, buscando compreender os prejuízos à constituição subjetiva e a relação com a alteridade
\end{abstract}


envolvidos nessa condição. Os resultados indicam que características vocais peculiares surgem em momentos de grande excitação ou situações com grande carga afetiva. Conclui-se que a avaliação diagnóstica baseada nas características acústicas da resposta sonora é problemática, já que desconsidera a dimensão social que está no cerne do autismo.

Palavras-chave: autismo, psicanálise, musicalidade, linguagem.

\section{ABSTRACT}

The sound qualities of vocal expressions by subjects with autism have received an increasing attention by the academic and clinical community. This article presents the results related to this topic from a research about a music group offered to children with autism. Two vocalizations occurred in the sessions are presented, as well as their respective acoustic analysis. The common features of vocalizations associated with autism, and the development of the psychic function of voice are discussed, trying to understand the damage to the subjective constitution and the relationship with otherness involved in this condition. The results indicate that particular vocal characteristics arise in times of great excitement or situations with great emotional charge. It is concluded that a diagnostic evaluation based on the acoustic characteristics of the sound response is problematic, since it disregards the social dimension that is on the core of autism.

Keywords: autism, psychoanalysis, musicality, language.

\section{INTRODUÇÃO}

O autismo é um transtorno do desenvolvimento que implica prejuízo grave das habilidades de interação social e comunicação, com início na primeira infância e uma tendência evolutiva crônica. Indivíduos afetados por essa condição enfrentam sérios obstáculos para a socialização e aquisição da linguagem, apresentando comportamentos e interesses estereotipados, além de dificuldades no relacionamento interpessoal e escolarização. Apesar de não haver consenso sobre sua etiologia, a fenomenologia clínica sugere que o autismo envolveria algum tipo de deficit social (Wing \& Gould, 1979) ou da representação mental da alteridade (Baron-Cohen, Leslie, \& Frith, 1985), provavelmente devido a um distúrbio do mecanismo intersubjetivo inato (Trevarthen, Aitken, Papoudi, \& Robarts, 1998). Nesse sentido, as funções da linguagem, pensamento e comportamento seriam comprometidas porque o relacionamento com o outro estaria prejudicado desde as primeiras etapas da vida.

Entre as diversas modalidades de tratamento para crianças com autismo, técnicas baseadas na música vêm sendo empregadas com relativo êxito, melhorando as habilidades de interagir e se expressar (Gold, Wigram, \& Elefant, 2008), 
aumentando as respostas comunicativas (Edgerton, 1994), e modificando e desenvolvendo padrões de relação social em aplicações a longo prazo (Schumacher \& Calvet-Kruppa, 1999). Com essa justificativa, realizou-se uma investigação sobre os efeitos terapêuticos de uma oficina de música oferecida a crianças com autismo com o objetivo de averiguar se a sua musicalidade poderia ser abordada em uma intervenção baseada no uso de canções que se relacionassem com sua identidade sonora e instaurassem um campo possível para o surgimento de movimentos expressivos e de interação social (Avila, 2015), cujos procedimentos e metodologia de análise empregados são detalhados na próxima seção.

Entre os tópicos abordados pela pesquisa, as qualidades sonoras das expressões vocais de sujeitos com autismo suscitaram diversos questionamentos, dada a sua relevância para compreender a musicalidade que se pretendia estudar. Trata-se ademais de um tema que vem recebendo uma crescente atenção por parte da comunidade acadêmica e clínica, encorajando pesquisas sobre a identificação do autismo a partir das características acústicas das vocalizações, por meio de algoritmos que poderiam ser aplicados já no primeiro ano e meio de vida (Santos et al., 2013). Outro exemplo é o LENA (Language Environment Analysis), um sistema composto por roupas especiais e um dispositivo de gravação, comercializado com o intuito de identificar rapidamente tais casos utilizando registros das produções vocais da criança (Richards, Xu, \& Gilkerson, 2010).

\section{PROCEDIMENTOS}

A oficina de música ocorreu entre 03/05 e 06/12/13, em um total de 20 sessões, com frequência semanal e duração de uma hora. As sessões foram realizadas no Instituto de Psicologia da Universidade de São Paulo, como parte de um programa de tratamento de psicopatologias da infância oferecido pelo Núcleo de Educação Terapêutica desta instituição. Antes da oficina, outro grupo terapêutico era oferecido, com atividades variadas como brincadeiras, jogos, escrita etc. Além desses dispositivos, os participantes tinham sessões de terapia individual de uma hora por semana, oferecidas por um aluno da graduação, em caráter de estágio, ou por um psicólogo do Núcleo.

O número de participantes da pesquisa foi de cinco crianças, entre 4 e 9 anos. Todos os sujeitos participantes da pesquisa tiveram um Termo de Consentimento Livre e Esclarecido preenchido pelos pais ou responsáveis em uma reunião na qual foram informados pelo pesquisador sobre os objetivos e procedimentos empregados, garantindo-lhes o sigilo e confidencialidade dos dados. Nesse sentido, seus nomes serão substituídos no presente artigo de modo a preservar sua identidade. 
A proposta das oficinas era a de "fazer música", estimulando o uso de instrumentos musicais diversos, tais como tambores, xilofone, chocalhos, flautas e apitos variados. Esses instrumentos eram primeiramente selecionados em função do número de participantes presentes e a estratégia a ser empregada naquele dia. A oficina então se iniciava com as crianças e adultos sentando-se em roda e procedendo à escolha dos instrumentos, seguido da apresentação de uma canção de abertura, na qual cada um se apresentava junto com seu instrumento no momento em que era chamado pela canção. O final das sessões também era definido por uma canção de encerramento, na qual, após apresentar os instrumentos, pedia-se às crianças que os guardassem.

Os procedimentos empregados foram a improvisação musical, o jogo musical e a recriação de canções. A improvisação musical (Bruscia, 2000; Wigram, 2004) corresponde a todo tipo de improvisação livre ou estruturada empregando múltiplos recursos sonoros, tais como voz, sons corporais ou instrumentais, visando o desenvolvimento de habilidades comunicativas e a capacidade de interação social. Já o jogo musical (Martinez, 2009) abarca as atividades lúdicas definidas em função da presença de padrões rítmicos e melódicos recorrentes, como as brincadeiras de roda, que estimulam a socialização e o contato com o outro pelo fato de dar as mãos e estabelecer movimentos coordenados.

Por fim, a recriação musical (Bruscia, 2000) inclui a execução, apresentação, transformação e interpretação de um modelo existente. No nosso caso, as recriações mais frequentes eram de canções, as quais podem ser divididas em quatro categorias. Em primeiro lugar, as canções infantis tradicionais, parte do folclore popular e da cultura. Em seguida, canções de um repertório infantil contemporâneo, sobretudo de desenhos animados e programas de televisão. Outro tipo é a canção improvisada, na qual letra, ritmo, melodia e harmonia são improvisados, sendo que ao menos parte desses elementos pode ser incorporado de um modelo já existente. Por último, as canções pessoais (Dreher, 2005) são compostas em razão da história e das interações da criança com o terapeuta, a partir de conteúdos verbais e não verbais que possuem um significado importante para ela.

As sessões da oficina foram gravadas com uma câmera de vídeo digital e o material foi transferido para um computador pessoal. Os vídeos foram analisados em momentos distintos da pesquisa: para as reuniões de supervisão, em que trechos das sessões eram empregados para apoiar as discussões; na edição de um vídeo de fim de ano, em que cenas foram selecionadas para serem apresentadas aos participantes e seus pais; e na elaboração dos estudos de caso, nos quais as imagens possibilitam a ilustração de um argumento ou a melhor compreensão de algum evento específico. Essas repetidas visualizações do material permitiram ao 
pesquisador uma familiaridade com os eventos ocorridos e o acompanhamento do processo terapêutico como um todo.

Todo o material reunido foi visto e anotado minuto a minuto. Alguns segmentos foram selecionados para uma análise mais detalhada porque poderiam oferecer uma melhor compreensão de dados que dificilmente seriam captados durante as sessões ou mesmo na reprodução da gravação ou porque ofereciam uma ilustração dos eventos ocorridos nas sessões. Esses segmentos foram então microanalisados por meio do congelamento de imagens, reprodução em câmera lenta, quadro a quadro e em loop.

A análise acústica (Malloch, 1999) foi empregada todas as vezes em que se buscou um maior detalhamento das qualidades acústicas de um segmento. Ela foi usada tanto na análise de eventos musicais quanto vocais, com o objetivo de fornecer uma avaliação quantitativa e qualitativa dos eventos sonoros. Com esse propósito, os registros sonoros selecionados foram submetidos ao software Praat (Boersma \& Weenink, 2012), ferramenta de análise acústica desenvolvida pela Universidade de Amsterdã, produzindo gráficos de análise espectral - ou espectrogramas -, e de pitch para cada segmento. Os espectrogramas são representações gráficas da frequência fundamental e harmônicos das emissões sonoras, medidos em $\mathrm{Hz}$, com as verbalizações discriminadas na parte inferior. Quanto mais intenso um harmônico, mais forte será a sua tonalidade na escala de cinza. Os gráficos de pitch, por sua vez, indicam a frequência fundamental do som emitido, isto é, a nota que de fato escutamos, que, no caso da voz, é definida pelo número de vibrações por segundo produzidas pelas cordas vocais.

Com relação à voz, a análise acústica pode oferecer informações objetivas a respeito da qualidade vocal, ou seja, do aspecto subjetivamente percebido das expressões vocais. Este pode ser descrito em termos da percepção auditiva como normal/anormal, bom/ruim, brilhante/escuro, oral/nasal etc., características que indicam um estado emocional ou um elemento diferencial de um indivíduo ou grupo de indivíduos. A qualidade da voz corresponde a um nível extralinguístico da comunicação, sendo determinada pelas características físicas e fisiológicas incluídas na produção vocal, como fatores orgânicos, de gênero, idade, extensão vocal etc.

A análise acústica das interações sociais vem sendo empregada na pesquisa em psicologia do desenvolvimento (Fernald, 1985; Fernald \& Kuhl, 1987; Trevarthen \& Malloch, 2009) e psicopatologia infantil (Muratori \& Maestro, 2007; Laznik, Maestro, Muratori, \& Parlato, 2005), e seu uso é recomendado por ser capaz de fornecer mensurações objetivas, tanto quantitativas quanto qualitativas, de parâmetros antes subjetivamente definidos como timbre, coordenação e sin- 
cronia. Essa metodologia será exemplificada na seção seguinte, na qual serão apresentadas duas vocalizações registradas na oficina de música, bem com suas respectivas análises.

\section{RESULTADOS}

Mathias é uma criança de 5 anos que é enviado ao Núcleo por indicação de sua creche. Segundo os educadores, recusa o contato dos adultos desde os primeiros dias de aula, desviando o olhar ou ficando calado quando tentam se comunicar com ele. Também evita a companhia das outras crianças, permanecendo afastado ou circulando pela creche. Chora frequentemente e apresenta poucos momentos de brincadeira simbólica. Na primeira sessão da oficina em que participa, Mathias se senta de costas para o grupo, tocando um xilofone e acompanhando o ritmo das canções. Sua progressiva inclusão nas propostas é facilitada pelo interesse pela música e os instrumentos, além do vínculo que estabelece com os adultos. $\mathrm{O}$ mesmo não se pode dizer com relação às demais crianças, com as quais ele mantém certa distância, por exemplo, permanecendo na roda enquanto estas saem correndo e brincam ao nosso redor.

Desde o início do tratamento, a equipe clínica reconhece momentos em que a voz de Mathias apresenta uma qualidade sonora distinta. A modo de exemplo, apresentamos uma vocalização na sessão de 24/05/13, na qual o grupo organiza uma festa de aniversário surpresa para mim. Aproveito o tema e pergunto a ele: "Quantos anos você tem?". Mathias me responde de forma ecolálica: "Quantos anos você tem?”. Digo a ele minha idade e ele passa a perguntar a idade dos demais. Depois, vai até a janela e olha para a persiana, tocando-a. Um estagiário, com a câmera, se aproxima dele e pergunta novamente a sua idade, mas o menino fica em silêncio e sorri. Sugerimos então que Mathias não quer dizer a idade, mas ele sai do silêncio e diz uma frase longa e ininteligível, com as palavras unidas e pronunciadas quase que silabicamente. A frase toda parece ser pronunciada por outra pessoa, pois o ritmo e a melodia não são os mesmos que ele costuma empregar. A única parte que entendemos é algo como "faltam quarenta e quatro dias". A psicóloga que o atende individualmente lhe pergunta: "Faltam quarenta e quatro dias para o quê?". "Para chegar o junho", diz Mathias, "o 31 de junho". Então perguntamos: "Quantos anos você vai fazer em 31 de junho?”, mas Mathias volta a falar algo incompreensível, com o mesmo ritmo e elisão entre as sílabas. Ele parece estar com uma agitação crescente, como se o tema o estivesse excitando, dirige-se até a porta e volta. Com os dedos da mão direita segurando a outra mão fechada, ele diz uma última frase, cuja análise acústica é apresentada 
(Figura 1). Como a primeira palavra coincidiu com o som de uma porta se fechando, preferiu-se omiti-la da análise, indicando-a entre colchetes.
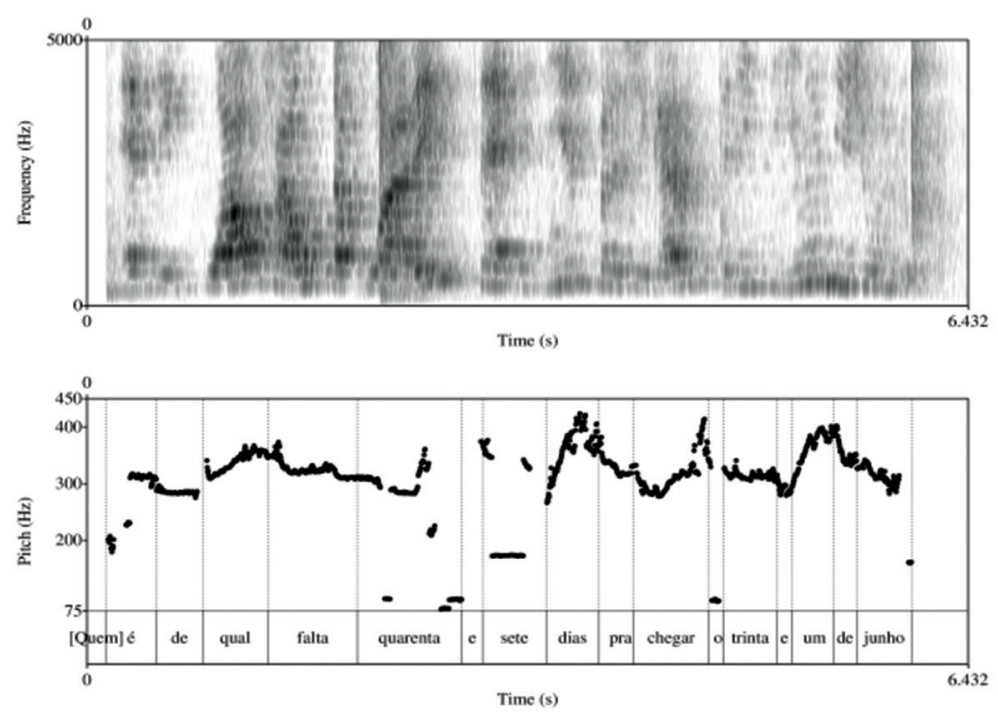

Figura 1 Análise espectral e de pitch de vocalização de Mathias na oficina de música de 24/05/13.

Para além do conteúdo da fala - que poderia ser considerado numérica e gramaticalmente incoerente -, sua forma também desperta o nosso interesse. Com a ajuda do espectrograma, é possível perceber que ela possui uma característica acústica peculiar, com tons de contornos acentuados, na forma de picos prosódicos. Podemos notar também que as palavras são emendadas umas às outras, sem uma pausa que as separe. Essas características conferem à expressão vocal uma qualidade melodiosa, quase que "cantada", que identificamos como sendo uma "outra voz".

Assim como Mathias, William é outro participante que em diversos momentos demonstra uma qualidade vocal distinta das que emprega usualmente. Trata-se de uma criança de 9 anos, com um diagnóstico de distúrbio global do desenvolvimento, dado pela pediatra, e diversas queixas das escolas pelas quais passou, desde falta de atenção até agressões a outras crianças. Apresenta também um discurso sem coerência, muitas vezes parecendo reproduzir falas ouvidas na televisão e juntando significantes em neologismos ou aglutinações. Seus movimentos corporais também chamam a atenção, pois William se revela bastante agitado e desajeitado, com dificuldade para manter-se quieto e reconhecer as partes de seu corpo como juntas em um todo, por exemplo, quando logo após uma situação que lhe parece engraçada, afirma que é a sua barriga que está rindo. 
Essa multiplicidade desunida nos faz pensar também na quantidade de timbres diferentes que ele parece ser capaz de empregar em seu discurso. Em diversas situações, ouvimos uma voz que não parece ser a sua, mas sim extraída de um programa de televisão. Isso fica mais evidente quando o ouvimos imitar de fato as aberturas dos desenhos animados, as vinhetas dos canais infantis ou falas que identificamos como sendo de algum personagem. Essas qualidades sonoras, no entanto, se repetem também em momentos no quais ele parece mais excitado, tomado por algum afeto de alegria ou surpresa. Nesses casos, o conteúdo da sua fala parece ser próprio, mas a forma não. A seguir, a análise acústica de uma vocalização sua na oficina de 14/06/13 é apresentada como um exemplo dessa "outra voz" que William parece empregar em determinadas situações (Figura 2). Após ter pedido para gravar a oficina com a câmera, pedimos que ele a devolva e se junte à roda. Há uma excitação motora que podemos perceber no modo como a câmera treme, e William parece estar emocionalmente tomado pelo ato de gravar o grupo. Ele rejeita nosso pedido, mandando-nos procurar um instrumento e tocar. Há uma diferença na qualidade vocal empregada nesse momento que é facilmente perceptível. A voz se torna rouca e grave, como se estivesse sendo produzida no fundo da garganta, mas também com pouca ressonância, parecendo que William comprime os maxilares e os dentes ao falar.

A análise espectral confirma a impressão subjetiva das qualidades vocais dessa vocalização. Primeiramente, há uma faixa intensa de harmônicos graves, $\mathrm{o}$ que confere à voz o aspecto gutural e rouco. Podemos ver como ela se alterna com a linha de pitch mais aguda, indicando que esse componente mais grave assume por alguns momentos o componente espectral fundamental e constitui a altura que de fato escutamos. Apesar dessa instabilidade harmônica, o contorno melódico principal apresenta uma variação mínima, com picos prosódicos pouco acentuados e praticamente lineares. Essa variação reduzida das alturas confere à vocalização seu caráter monótono, associada à ideia de que ele comprime os maxilares e os dentes enquanto a enuncia.

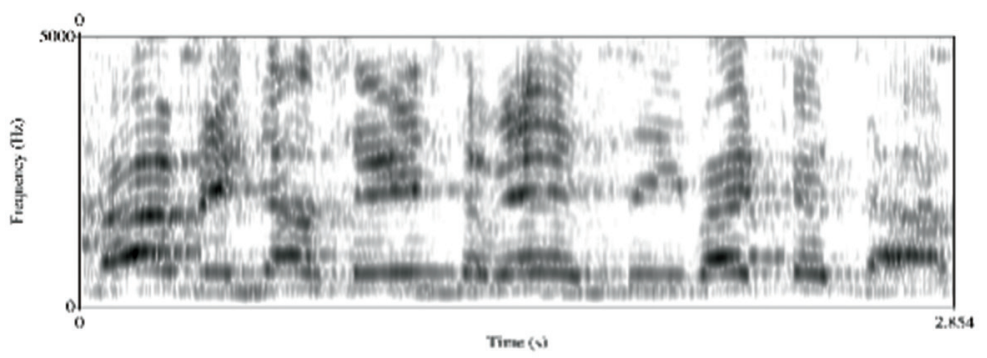




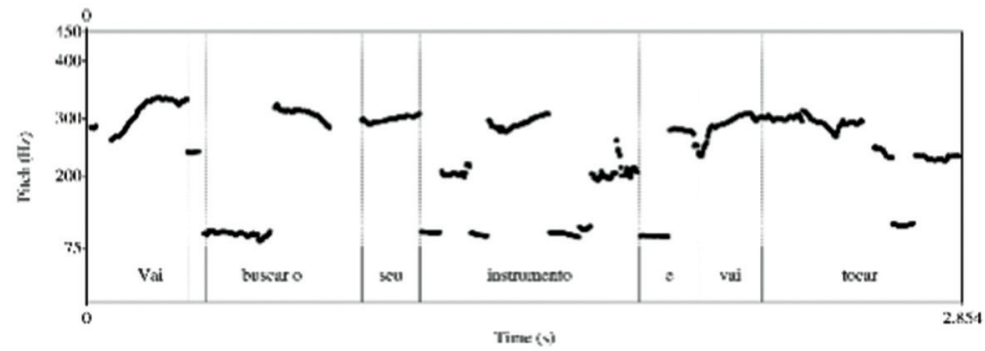

Figura 2 Análise espectral e de pitch de uma vocalização de William na oficina de música do dia 14 de junho de 2013.

Diríamos também que ela expressa uma qualidade emocional equivalente, pois confere ao enunciado um tom mais imperativo, talvez com a intenção de aumentar sua eficácia enquanto ordem. Porém, o mais importante seria ressaltar que essa qualidade vocal surge frequentemente nas sessões da oficina, em situações variadas e nas quais pode ser evidente ou não que ele está encenando a fala de um outro personagem ou fazendo algum pedido ou ordem. Isso torna difícil estabelecer o seu sentido, porém é possível notar que ela geralmente acompanha um estado de excitação, por um motivo qualquer. No final, a voz representa mais um elemento indicador da experiência subjetiva fragmentada que acreditamos ser a de William.

\section{DISCUSSÃo}

Um dos aspectos mais intrigantes do trabalho com crianças com autismo é a sua voz. Existe uma grande atenção na literatura a esse respeito, geralmente focada na ausência ou baixa frequência de produção vocal, ainda que uma parte desse foco se dirija também às especificidades do seu uso. Segundo Wing (1996), pessoas com autismo possuem dificuldades com a entonação e o controle da voz. Isso implica uma produção vocal peculiar, que pode ser monótona ou carregada de inflexões inadequadas, ou com um volume de fala alto ou baixo demais. A autora propõe que a voz pode ter também uma qualidade timbrística mecânica, semelhante à de um robô.

Em uma análise acústica realizada por DePape, Chen, Hall e Trainor (2012), adultos com autismo empregaram uma extensão limitada de alturas para responder a perguntas sobre imagens projetadas na tela de um computador. Mesmo indivíduos com um grau menos severo de autismo tampouco usaram a prosódia para marcar a estrutura de informações dos enunciados, apesar de usar uma gama maior de frequências fundamentais. Já em um estudo com crianças com e 
sem autismo, Bonneh, Levanon, Dean-Pardo, Lossos e Adini (2011) encontraram nas primeiras uma extensão e variabilidade maiores que nas do segundo grupo. Essa variabilidade e extensão das frequências fundamentais sugere, de fato, que sua voz seria mais melódica, ou possuiria contornos prosódicos mais exagerados. Para esses pesquisadores, essa diferença resultaria de déficits nos mecanismos que controlam o pitch da voz, em sua produção ou recepção, possivelmente associados a um processamento auditivo anormal mais geral.

Pela semelhança dessas características com as do parentês - tipo de fala orientada aos bebês, caracterizada por sílabas alongadas, com frequências agudas e modulações de altura que formam um contorno melódico específico (Fernald, 1985) -, Sharda et al. (2010) deduzem que essas crianças apresentariam uma trajetória de fala atrasada. Por outro lado, Wing (1996) sugere que aquilo que reconhecemos nessas crianças como sendo uma "outra voz" ou uma "voz especial" poderia ser uma cópia de algo que escutaram ou uma tentativa de provar sons diferentes. De fato, a experimentação vocal é algo próprio das crianças. Para elas, é atrativo brincar com as vocalizações, imitar as vozes dos outros, os sons dos objetos, dos animais etc. Aos 5 anos, apresentam uma variabilidade espectral e temporal na fala muito maior que adultos ou crianças mais velhas, seja entre uma criança e outra da mesma idade, seja a mesma em diferentes momentos e para diferentes palavras e sons (Gerosa, Lee, Giuliani, \& Narayanan, 2006).

Essa variação nas características vocais é efeito tanto das mudanças anatômicas e fisiológicas no desenvolvimento orgânico quanto da crescente habilidade na produção e articulação de sons. Com o passar do tempo, espera-se que a voz se torne cada vez mais uniforme, isto é, que a variação no mesmo sujeito dos parâmetros acústicos seja reduzida conforme aumenta a idade, sobretudo até os 11 ou 12 anos (Lee, Potamianos, \& Narayanan, 1999). Durante o período dos 11 aos 15 anos, surge uma diferenciação na variabilidade da qualidade vocal entre meninos e meninas, pois as mudanças nas frequências dos formantes dos primeiros apresentam uma linearidade conforme a idade, o que não é tão evidente para as meninas.

Além disso, logo as crianças aprendem que as variações melódicas do discurso obedecem a normas socialmente convencionadas, já que, como nota Austin (1962), o movimento ascendente ou descendente de pitch confere ao enunciado uma característica afetiva (por exemplo, tristeza ou alegria) ou pragmática (por exemplo, exclamação ou interrogação). Tal código fonético comum é fundamental para o compartilhamento das intenções entre interlocutores e permite o desenvolvimento da competência linguística e da própria comunicação em si. Evidentemente, esse não é o caso das expressões apresentadas aqui, tendo em vista o estranhamento que as mesmas despertam. Pareceria mais que se trata de variações que levam o discurso à beira da linguagem falada e seu modo de produção de sentido, deslocando-a para o campo da música e da palavra cantada. 
De fato, o canto é algo que se adiciona à fala, se considerarmos as notas da melodia como uma informação adicional ao texto, que altera sua entonação, intensidade e ritmo, tanto ressaltando sentidos ocultos quanto fazendo com que significados explícitos passem despercebidos. Como sugere Zuckerkandl (1976), a canção agrega um elemento significante ao código da linguagem, atualizando uma nova dimensão da palavra e de seu sentido. A ideia de dimensão pode ser entendida aqui literalmente, como em geometria: com a nota, a palavra ganha profundidade, volume e espessura, como se recebesse dela uma "outra camada de realidade" (p. 44). Cantar leva a voz do sujeito de volta ao primeiro plano da fala, às custas do significado socialmente convencionado das palavras.

Com efeito, a relação da prosódia da voz com o gosto e o prazer da escuta musical demonstra que existe na fala algo que é irredutível ao sentido, isto é, que não existe em função da sua inteligibilidade ou da capacidade de transmitir um conteúdo representacional. Há uma dimensão da voz que não caracteriza nenhum objeto no mundo senão o próprio sujeito e seu desejo. Como destaca Kauffman (1998), se atentarmos para as modulações da voz e o ritmo da elocução do discurso, por exemplo, observamos que ele raramente é homogêneo: "Ora grave, ora aguda - ora colorida, ora 'branca' -, ora regular, ora precipitada, a voz habita as palavras a ponto de indicar o que poderíamos chamar de variações tópicas no discurso" (p. 696), ou seja, que indicam as flutuações subjetivas associadas às representações psíquicas dos enunciados.

Desse modo, tão logo nos concentramos no sentido da fala, perdemos a percepção consciente das qualidades particulares da voz, cuja materialidade se opõe à idealidade do significado, aproximando a voz daquilo que não contribui para fazer sentido (Miller, 1989). Segundo Dolar (2006), são três os aspectos da voz que contribuem à sua recalcitrância ao significante: o sotaque, que leva a voz à vizinhança do cantar; a entonação, que altera o sentido dos enunciados, até mesmo os transforma ironicamente em seu oposto; e o timbre, isto é, o modo particular de cada pessoa produzir sons, sua característica reconhecível e identificável. As modulações estudadas aqui parecem não ser explicada apenas por um sotaque ou a entonação intencional com o objetivo de determinar o sentido dos enunciados, devendo ser também lidas nessa chave do timbre da voz.

Portanto, para além dos seus aspectos intersubjetivos e socioculturais, existe uma dimensão relacionada à função psíquica da voz (Dolar, 2006), cuja constituição remete aos primeiros eventos comunicativos - que já comportam uma elaborada capacidade expressiva da voz -, e que se prolonga após a aquisição da linguagem de tal modo que sustenta a musicalidade da fala. Mais do que uma habilidade, essa peculiaridade da comunicação humana está diretamente envolvida nos primórdios da constituição da subjetividade. Assim, apesar de corresponder a estados mentais internos, ela está igualmente ancorada na relação com a 
alteridade, já que está envolvida na ativação de um circuito pulsional que produz no corpo orgânico a primeira dinâmica interativa com a alteridade.

Ao longo do desenvolvimento, a musicalidade é, portanto, um fator determinante para o início e apoio das relações intersubjetivas, muito antes que estas sejam intermediadas pela linguagem (Trevarthen \& Malloch, 2009). Deve-se a ela a existência de uma verdadeira pré-linguagem de intenções e emoções (Papoušek, 1996), de modo que essa capacidade precoce de percepção e produção de sons é o que torna possível as primeiras interações vocais entre o bebê e seu cuidador (Bateson, 1979). Após a entrada na linguagem, a musicalidade da voz segue veiculando sua função psíquica invocante, em detrimento das funções linguísticas. Esse movimento corresponde ao que Lecourt (2011) chama de desmame musical, que conduz a musicalidade ao psiquismo inconsciente. Inconsciente porque a voz se converte em uma espécie de silêncio da fala. Não um silêncio como falta ou ausência da fala, mas sim aquilo que dela não se percebe conscientemente.

Mesmo antes do nascimento, os picos prosódicos emitidos pela mãe, ao chegar aos ouvidos da criança, estabelecem zonas erógenas ao mesmo tempo em que a voz se constitui como um dos primeiros objetos da pulsão (Laznik, 1999), elemento fundador do audível. Essa anterioridade da voz com relação aos demais objetos pulsionais, como o olhar, o seio da mãe ou outras partes do corpo, coloca-a no centro da primeira forma de funcionamento psíquico (Catão, 2009), se considerarmos as pulsões como o aspecto originário da subjetividade (Freud, 1905/1976).

Em realidade, como aponta Vasse (1997), a voz está presente no psiquismo antes mesmo da constituição do eu, como um conjunto psíquico pré-individual, um esboço de unidade e identidade. Mais tarde, tomada como envelope sonoro, a voz "entra na estruturação posterior do eu, da mesma forma, diríamos, que a imagem especular" (Kauffman, 1998, p. 696). Nesse sentido, o movimento da voz compõe um circuito à pulsão invocante (Lacan, 2005), no qual a energia psíquica pode circular, criando uma primeira forma de laço social e, como as ondas do oceano, formar o litoral entre o sujeito e o Outro (Catão, 2009). É justamente uma falha na instauração do circuito pulsional que define que um sujeito se torne autista, com um simultâneo comprometimento do laço social (Laznik, 1998; Catão, 2009). Laznik, Maestro, Muratori, \& Parlato (2005), analisando vídeos com bebês que se tornaram autistas e seus pais, concluíram que as interações sonoras entre eles não apresentam as características usuais do parentês, e que as crianças, por sua vez, eram mais atraídas pelos objetos que pelas pessoas que as chamavam. Isso indicaria um prejuízo à elaboração da função psíquica da voz e, consequentemente, de toda a constituição subjetiva e da relação com a alteridade, o que poderia implicar nas características acústicas peculiares das vocalizações de sujeitos com autismo. 


\section{CONCLUSÃO}

Com relação ao método empregado, um primeiro destaque pode ser dado ao emprego dos grupos terapêuticos. Para além de seus objetivos clínicos, eles podem ser considerados ferramentas úteis no estudo da experiência musical, de um modo geral, já que permitem a observação, acompanhamento e intervenção no nível da prática, semelhante àquela que os participantes poderiam ter em casa, na escola, em oficinas de educação musical etc. Se bem esse método proporciona uma compreensão de como as crianças agem dentro de um contexto social mediado pela música, ele pode não ser o mais indicado para o estudo das caraterísticas acústicas de verbalizações, por exemplo, já que dificilmente se consegue obter uma amostra pura desses objetos, sem a concorrência de sons ambientes ou produzidos pelos demais participantes. É nesse sentido que a presente pesquisa pôde oferecer resultados inconclusivos a esse respeito, não obstante a indicação de que o mesmo pode ser um campo fértil para pesquisas baseadas em outros métodos de estudo e observação.

Durante as sessões, os participantes frequentemente apresentavam verbalizações com qualidades vocais particulares, em termos de entonação e prosódia, distintas daquelas que empregavam usualmente. A análise acústica de uma vocalização apresentou contornos prosódicos acentuados e poucas pausas entre as palavras. Já outra vocalização revelou uma variação mínima de frequência e uma faixa de harmônicos graves, que conferiam à voz um aspecto gutural e rouco. Chama a atenção que essa "outra voz" surge em momentos de grande excitação, seja por uma brincadeira mais enérgica, ou ao apresentar motivos que parecem afetivamente mais carregados que os demais. É possível que essas características sejam imitadas de pessoas ou personagens, o que tampouco pode ser confirmado, dada a variedade de situações e contextos nos quais podem surgir.

Tais ocorrências de uma qualidade sonora diferente ou especial nas expressões vocais registradas, no entanto, parecem estar associadas a um contexto afetivo intenso, no qual as crianças pareciam tomadas por uma excitação emocional. Isso indica que existe um fator ligado à experiência subjetiva que determina a qualidade das vocalizações, irredutível a uma estruturação puramente orgânica, seja do aparelho fonador ou do sistema auditivo. Em um nível intrapsíquico, esses eventos podem ser relacionados ao desenvolvimento da função psíquica da voz e movimentos de emergência subjetiva na ordem da linguagem. É possível que problemas de constituição dessa função estejam implicados nesses fenômenos, e que a dimensão desejante do sujeito tenha que ser levada em conta na sua explicação.

De qualquer modo, mais que uma estratégia discursiva intencional, ou um processo de identificação, tais apropriações parecem confirmar a experiência subjetiva fragmentada de que esses sujeitos muitas vezes demonstram ter. Trata-se de um aspecto que pode ser de grande relevância para futuros estudos, capazes de 
remeter tais características não apenas às propriedades acústicas da voz, mas também à sua função comunicativa, inserida no campo das interações sociais e da constituição psíquica.

Considerando a situação atual dos tratamentos disponíveis para o autismo, ainda incapazes de oferecer um prognóstico de cura no sentido da remissão completa dos sintomas e a retomada das funções do desenvolvimento em um nível considerado típico, os esforços por uma detecção precoce - que permita realizar intervenções oportunas -, são de grande valor para esta população. No entanto, esse trabalho deve ser feito com muita cautela e crítica. Assim, não deixa de ser preocupante que uma caracterização normativa da voz seja utilizada para a identificação precoce do autismo. Não se pode minimizar os riscos de proceder uma avaliação desse porte baseada exclusivamente nas características acústicas da resposta sonora, desvinculada de seu contexto social e sua significação em uma dinâmica comunicacional interativa. Isso seria considerar o autismo como um transtorno da comunicação verbal, desconsiderando a dimensão social que está no cerne da sua constituição.

\section{REFERÊNCIAS}

Alvin, J., \& Warwick, A. (1992). Music Therapy for the Autistic Child. Oxford: Oxford University Press.

Austin, J. L. (1962). How to do things with words. Londres: Oxford University Press.

Avila, D. C. (2015). A musicalidade comunicativa das canções: um estudo sobre a identidade sonora de crianças com autismo. (Tese de Doutorado). Universidade de São Paulo, Instituto de Psicologia, São Paulo, Brasil.

Baron-Cohen, S.; Leslie, A.M.; Frith, U. (1985). Does the autistic child have a 'theory of mind'? Cognition, 21, 37-46.

Bateson, M. C. (1979). The epigenesis of conversational interaction: A personal account of research development. In: M. Bullowa (Ed.) Before Speech: The beginning of human communication (p. 63-77). Londres: Cambridge University Press.

Boersma, P., \& Weenink, D. (2012). Praat: doing phonetics by computer, version 5.3.19 [Programa de computador]. Amsterdã: University of Amsterdam. Recuperado de http://www.praat.org.

Bonneh, Y. S., Levanon, Y., Dean-Pardo, O., Lossos, L., \& Adini, Y. (2011). Abnormal speech spectrum and increased pitch variability in young autistic children. Frontiers in Human Neuroscience, 4, 1-7.

Bruscia, K. E. (2000). Definindo musicoterapia. Rio de Janeiro: Enelivros.

Catão, I. (2009). O bebê nasce pela boca: voz, sujeito e clínica do autismo. São Paulo: Instituto Langage. 
DePape, A.-M. R., Chen, A., Hall, G. B. C., \& Trainor, L. J. (2012). Use of prosody and information structure in high functioning adults with Autism in relation to language ability. Frontiers in Psychology, 3, 1-13.

Dolar, M. (2006). A voice and nothing more. Cambridge: Massachusetts Institute of Technology Press.

Dreher, S. C. (2005). A canção: um canal de expressão de conteúdos simbólicos e arquetípicos. Psicologia Argumento, 23(42), 127-144.

Edgerton, C. L. (1994). The effect of improvisational music therapy on the communicative behaviors of autistic children. Journal of Music Therapy, 31(1), 31-62.

Fernald, A. (1985). Four-month-old infants prefer to listen to motherese. Infant Behavior and Development, 8(2), 181-195.

Fernald, A., \& Kuhl, P. (1987). Acoustic determinants of infant preference for motherese speech. Infant Behavior and Development, 10(3), 279-293.

Freud, S. (1976). Três ensaios sobre a teoria da sexualidade. In: Freud, S. Edição Standard Brasileira das Obras psicológicas completas de Sigmund Freud, v. 7, p. 157-246. Rio de Janeiro: Imago. (Trabalho original publicado em 1905).

Gerosa, M., Lee, S., Giuliani, D., \& Narayanan, S. (2006) Analyzing children's speech: an acoustic study of consonants and consonant-vowel transition. Proceedings of the International Conference on Acoustics, Speech, and Signal Processing, p. 393-396. Toulose: ICASSP.

Gold, C., Wigram, T., \& Elefant, C. (2008). Musicoterapia para el trastorno de espectro autista. La Biblioteca Cochrane Plus, 2, 1-20.

Kaufmann, P. (1998). Dicionário enciclopédico de psicanálise: o legado de Freud e Lacan. Rio de Janeiro: Zahar.

Lacan, J. (2005). O Seminário Livro X: a angústia. Rio de Janeiro: Zahar.

Laznik, M.-C. (1998). O que a clínica do autismo pode ensinar aos psicanalistas. Salvador: Álgama.

Laznik, M.-C. (1999). La voix comme premier objet de la pulsion orale. Psychanalyse et enfance, 28, 101-117.

Laznik, M.-C., Maestro, S., Muratori, F., \& Parlato, E. (2005). Interações sonoras entre bebês que se tornaram autistas e seus pais. Colóquio franco-brasileiro sobre a clínica com bebês, Paris.

Lecourt, E. (2011). L'intervalle musical: entre l'autre et l'Autre. Insistance, 6, 119-132.

Lee, S., Potamianos, A., \& Narayanan, S. (1999). Acoustics of children's speech: developmental changes of temporal and spectral parameters. Journal of the Acoustical Society of America, 105(3), 1455-1468.

Malloch, S. N. (1999). Mothers and infants and communicative musicality. Musicae Scientiae, Special Issue 1999-2000, 29-57.

Martínez, M. (2009). Juego Musical y Trastornos del Espectro Autista. La experiencia artística y la cognición musical. Córdoba: Sociedad Argentina para las Ciências Cognitivas de la Música. 
Miller, J.-A. (1989). Jacques Lacan et la voix. In Fonagy, I., Lew, R., Sauvagnat, F., Fonagy, I., Kristeva, J., Lanteri-Laura, G., . . . Fliess, R. La voix: Actes du colloque d'Ivry, p. 175-184.. Paris: La lysimaque.

Muratori, F., \& Maestro, S. (2007). Autism as a Downstream Effect of Primary Difficulties. In: Intersubjectivity Interacting with Abnormal Development of Brain Connectivity. International Journal for Dialogical Science, 2(1), 93-118.

Papoušek, H. (1996). Musicality in infancy research: Biological and cultural origins of early musicality. In: I. Deliège \& J. Sloboda (Eds.). Musical Beginnings: Origins and Development of Musical Competence, p. 37-55. Nova York: Oxford University Press.

Richards, J. A., Xu, D., \& Gilkerson, J. (2010). Development and Performance of the LENA Automatic Autism Screen. Boulder: LENA Foundation.

Santos, J. F., Brosh, N., Falk, T. H., Zwaigenbaum, L., Bryson, S. E., Roberts, W., ... Brian, J. A. (2013). Very early detection of Autism Spectrum Disorders based on acoustic analysis of pre-verbal vocalizations of 18-month old toddlers. International Conference on Acoustics, Speech and Signal Processing, p. 7567-7571. Vancouver: Institute of Electrical and Electronics Engineers Signal Processing Society.

Schumacher, K., \& Calvet-Kruppa, C. (1999). The AQR - an analysis system to evaluate the quality of relationship during music therapy. Nordic Journal of Music Therapy, 8(2), 188-191.

Sharda, M., Subhadra T. P., Sahay, S., Nagaraja, C., Singh, L., Mishra, R., ... Singh, N. C. (2010). Sounds of melody--pitch patterns of speech in autism. Neuroscience Letters, 478, 42-45.

Trevarthen, C., Aitken, K., Papoudi, D., \& Robarts, J. (1998). Children with Autism: Diagnosis and Interventions to Meet Their Needs. Londres: Jessica Kingsley.

Trevarthen, C., \& Malloch, S. N. (2009). Musicality: Communicating the vitality and interests of life. In C. Trevarthen \& S. N. Malloch (Eds.) Communicative musicality: Exploring the basis of human companionship. p. 1-11. Nova Iorque: Oxford University Press.

Vasse, D. (1977). O umbigo e a voz: Psicanálise de duas crianças. São Paulo: Loyola.

Wigram, T. (2004). Improvisation: methods and techniques for music therapy clinicians, educators, and students. Londres e Filadélfia: Jessica Kingsley Publishers.

Wing, L., \& Gould, J. (1979). Severe Impairments of Social Interaction and Associated Abnormalitiesin Children: Epidemiology and Classification. Journal of Autism and Developmental Disorders, 9, 11-29.

Wing, L. (1996). El autismo en niños y adultos: una guía para la familia. Barcelona: Paidós.

Zuckerkandl, V. (1976). Man the musician. Princeton: Princeton University Press. 